\title{
Iron Homeostasis in Elite Athletes and Ultramarathon Runners ${ }^{\dagger}$
}

\author{
Katerina P. Skenderi ${ }^{1, *}$, George Papanikolaou ${ }^{1}$, Tzortzis Nomikos ${ }^{1}$, Yannis Kotsis ${ }^{1}$ and \\ Maria Tsironi ${ }^{2}$ \\ 1 Laboratory of Nutrition and Clinical Dietetics, Harokopio University, Athens 17671, Greece \\ 2 School of Nursing, University of Peloponnese, Sparta 23100, Greece \\ * Correspondence: ksken@hua.gr \\ + Presented at the 9th Greek Conference of Biochemistry and Physiology of Exercise, Thessaloniki, Greece, \\ 18-20 October 2019.
}

Published: 3 September 2019

\begin{abstract}
AIM: The present study was aimed at determining the effect of two different types of exercise (elite athletes playing football and ultramarathon runners on iron metabolism and, especially, the role of hepcidin in iron homeostasis. MATERIAL \& METHOD: Two groups of athletes were investigated. The first group consisted of 19 male elite football athletes and the second group of 41 ultramarathon runners. In both cases, blood samples were taken pre-race (t1), immediately post-race (t2), and 24 hours post-race for football athletes or 36-48 hours post-race for ultramarathon athletes (t3). RESULTS: The iron levels in time t3 were found to have statistically significant decreases compared with the iron levels in pre-race and post-race period. Moreover, ferritin levels increased significantly in times $\mathrm{t} 2$ and $\mathrm{t} 3$. Hepcidin levels increased in time $\mathrm{t} 2 \mathrm{in}$ football players (from $27.45 \pm 12.98$ to $37.42 \pm 13.74 \mathrm{ng} / \mathrm{mL}$ ) and decreased in time t3. However, in ultramarathon runners, hepcidin levels significantly increased in time t2 (from $29.16 \pm 10.92$ to 58.81 $\pm 16.97 \mathrm{ng} / \mathrm{mL})$ and remained increased in time t3 $(37.69 \pm 16.38 \mathrm{ng} / \mathrm{mL})$, despite a trend for decrease. In football players, sTfR levels did not change, contrary to ultramarathon runners, where sTfR levels were found decreased in times $\mathrm{t} 2$ and $\mathrm{t} 3$. CONCLUSIONS: Iron metabolism in athletes can be impacted by the type of exercise. Ferritin is not a reliable marker for iron balance because, in the present study, it is more likely an acute-phase protein. The main regulator of iron homeostasis, hepcidin, increased, showing the body's response to inflammation, by trapping iron in the macrophages and by altering iron absorption. Finally, a strenuous and prolonged exercise can lead to sports anemia.
\end{abstract}

Keywords: elite athletes; iron homeostasis; heart rate; ultramarathon

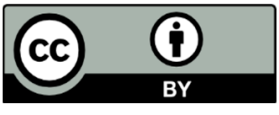

(C) 2019 by the authors. Licensee MDPI, Basel, Switzerland. This article is an open access article distributed under the terms and conditions of the Creative Commons Attribution (CC BY) license (http://creativecommons.org/licenses/by/4.0/). 